\title{
IMPLEMENTASI METODOLOGI SIX SIGMA UNTUK MENINGKATKAN KUALITAS PRODUK KURSI KULIAH
}

\section{Implementation of Six Sigma Methodology to Improve The Quality of Course Products}

\author{
Muhamad Faizal Aulya', Amin Syukron², Christian Soolany 1,* \\ ${ }^{1}$ Jurusan Teknik Mesin - Fakultas Teknologi Industri - Universitas Nahdlatul Ulama Al Gazali \\ ${ }^{2}$ Jurusan Teknik Industri - Fakultas Teknologi Industri - Universitas Nahdlatul Ulama Al Gazali \\ *Korespondensi, Email: christiansoolany@gmail.com \\ DOI: https://doi.org/10.20884/1.jaber.2021.2.1.4190 \\ Naskah ini diterima pada 5 Mei 2021; revisi pada 10 Mei 2021; \\ disetujui untuk dipublikasikan pada 19 Mei 2021
}

\begin{abstract}
ABSTRAK
Pengolahan citra adalah suatu metode yang digunakan untuk mengolah citra (image) sehingga Six sigma merupakan cara pendekatan kualitas terhadap Total Quality Management (TQM). TQM menjadi perhatian di Amerika Serikat tahun 80-an dan ini merupakan suatu respons terhadap superioritas kualitas dari pabrikan Jepang dalam bidang automotif dan penyejuk ruangan. Banyak studi pada bidang penyejuk ruangan mengemukakan bahwa kerusakan (defect) pada perusahaan Amerika Serikat lebih banyak dari perusahaan Jepang. Untuk membantu perusahaan supaya mampu memperbaiki program peningkatan kualitas, maka didirikan Malcolm Balridge National Quality Award dalam tahun 1987. Salah satu fasilitas yang mendukung kelancaran proses belajar dan mengajar di prodi Teknik Industri UNUGHA adalah kursi kuliah. Kondisi kursi kuliah yang digunakan saat ini adalah kursi dengan rangka dari besi kotak, alas duduk dari busa, sandaran punggung dari busa serta alas menulis dari kayu. Dari hasil penelitian, diperoleh kegagalan yang paling sering terjadi pada kursi tidak stabil dengan jumlah kerusakan 30 unit dan permasalahan dalam pembuatan kursi kuliah adalah kursi kuliah tidak stabil. Membuat kursi tidak siku, dalam masalah kegagalan produk kursi kuliah ini terjadi dalam proses pemasangan, dan orang yang bertanggung jawab adalah operator karena kurang telitinya saat pemasangan kursi kuliah sehingga kursi tidak siku membuat kursi tidak stabil. Solusinya operator harus lebih teliti dan menggunakan penggaris siku pada saat pemasangan kursi.
\end{abstract}

Kata kunci: six sigma, kursi kuliah, produksi

\begin{abstract}
Six sigma is a quality approach to Total Quality Management (TQM). TQM is a concern in the United States in the 80s and this is a response to the quality superiority of Japanese manufacturers in the field of automotive and air conditioning. Many studies in the field of air conditioning suggest that defects in US companies are more than those of Japanese companies. To help the company to be able to improve its quality improvement program, Malcolm Balridge National Quality Award was established in 1987. One of the facilities that support the smooth learning and teaching process at UNUGHA Industrial Engineering study program is the lecture chair. The condition of the lecture chair used today is a chair with an iron frame box, foam padded seat, foam backrest and wooden writing pad. From the results of the study, it was found that the most frequent failures in unstable chairs with 30 units of damage and the problem in making college chairs was the unstable lecture chair. Making a chair is not elbow, in the problem of failure of this lecture chair product occurs in the installation process, and the person in charge is the operator because of lack of rigor when installing the lecture chair so that the chair does not make the chair unstable. The solution is the operator must be more careful and use an elbow ruler when installing the seat.
\end{abstract}

Keywords: six sigma, college seats, production. 


\section{PENDAHULUAN}

Secara umum tujuan suatu industri manufaktur adalah untuk memproduksi barang secara ekonomis agar dapat memperoleh keuntungan serta dapat menyerahkan produk tepat waktu. Selain itu industri manufaktur juga ingin agar proses produksi dapat kontinyu dan berkembang sehingga kelangsungan hidup perusahaan terjamin. Sekarang ini perusahaan juga dituntut untuk lebih kompetitif sehingga mampu bersaing merebut pasar yang ada. Oleh karena itu perusahaan harus dapat menjalankan strategi bisnisnya yang tepat agar mampu bertahan dalam menghadapi persaingan yang terjadi.

Kemajuan dan perkembangan zaman merubah cara pandang konsumen dalam memilih sebuah produk yang diinginkan. Kualitas menjadi sangat penting dalam memilih produk disamping faktor harga yang bersaing. Perbaikan dan peningkatan kualitas produk dengan harapan tercapainya tingkat cacat produk mendekati zero defect membutuhkan biaya yang tidak sedikit. Perbaikan kualitas dan perbaikan proses terhadap sistem produksi secara menyeluruh harus dilakukan jika perusahaan ingin menghasilkan produk yang berkualitas baik dalam waktu yang relatif singkat. Suatu perusahaan dikatakan berkualitas bila perusahaan tersebut mempunyai sistem produksi yang baik dengan proses terkendali. Melalui pengendalian kualitas (quality control) diharapkan bahwa perusahaan dapat meningkatkan efektifitas pengendalian dalam mencegah terjadinya produk cacat (defect prevention), sehingga dapat menekan terjadinya pemborosan dari segi material maupun tenaga kerja yang akhirnya dapat meningkatkan produktifitas.

Six sigma merupakan cara pendekatan kualitas terhadap Total Quality Management (TQM). TQM menjadi perhatian di Amerika Serikat tahun 80-an dan ini merupakan suatu respons terhadap superioritas kualitas dari pabrikan Jepang dalam bidang automotif dan penyejuk ruangan. Banyak studi pada bidang penyejuk ruangan mengemukakan bahwa kerusakan (defect) pada perusahaan Amerika Serikat lebih banyak dari perusahaan Jepang. Untuk membantu perusahaan supaya mampu memperbaiki program peningkatan kualitas, maka didirikan Malcolm Balridge National Quality Award dalam tahun 1987.

Pada umumnya sistem pengendalian kualitas seperti TQM dan lain-lain hanya menekankan pada upaya peningkatan terus menerus berdasarkan kesadaran mandiri dari manajemen. Sistem tersebut tidak memberikan solusi yang tepat mengenai terobosan-terobosan atau langkah-langkah yang seharusnya dilakukan untuk menghasilkan peningkatan kualitas secara dramatik menuju tingkat kegagalan $=0$ (zero defect). Six sigma sebagai salah satu metode baru yang paling popular merupakan salah satu alternatif dalam prinsip-prinsip pengendalian kualitas yang merupakan terobosan dalam bidang manajemen kualitas (Gasperzs, 2005: 303) Six sigma dapat dijadikan ukuran kinerja sistem industri yang memungkinkan perusahaan melakukan peningkatan yang luar biasa dengan terobosan strategi yang aktual. Six sigma juga dapat dipandang sebagai pengendalian proses industri yang berfokus pada pelanggan dengan memerhatikan kemampuan proses. Pencapaian six sigma hanya terdapat 3,4 cacat per sejuta kesempatan. Semakin tinggi target sigma yang dicapai maka kinerja sistem industri semakin membaik.

Salah satu fasilitas yang mendukung kelancaran proses belajar dan mengajar di prodi Teknik Industri UNUGHA adalah kursi kuliah. Kondisi kursi kuliah yang digunakan saat ini adalah kursi dengan rangka dari besi kotak, alas duduk dari busa, sandaran punggung dari busa serta alas menulis dari kayu.

Berdasarkan deskripsi diatas, maka rumusan masalah dalam penelitian ini adalah bagaimana Implementasi Metodologi Six Sigma Untuk meningkatkan Kualitas Produk Kursi Kuliah. Penulisan karya ilmiah ini bertujuan bagaimana Implementasi metodologi Six Sigma untuk meningkatkan kualitas produk kursi kuliah. Manfaat dari penelitian ini adalah mengetahui implementasi metodologi Six Sigma untuk meningkatkan kualitas produk kursi kuliah. 


\section{METODE PENELITIAN}

\section{Pendekatan Penelitian}

Metode yang digunakan mengacu pada prinsip-prinsip yang terdapat dalam metode Six Sigma. Metode ini digunakan untuk mengantisipasi terjadinya kesalahan atau defect dengan menggunakan langkah-langkah terukur dan terstruktur. Dengan berdasar pada data yang ada, maka Continuous improvement dapat dilakukan berdasar metodologi Six sigma yang meliputi D (Define) M (Measure) A (Analyze) I (Improve) C (Control) (Pete\& Holpp, 2002: 45)

\section{Jenis dan Sumber Data}

Ada dua sumber data dalam penelitian ini antara lain sebagai berikut :

1. Dara primer, data yang diperoleh dari masyarakat yang membuat kursi kuliah yang menjadi tempat penelitian. Data yang diperoleh berupa data kuantitatif dan data kualitatif. Data kuantitatif yaitu data yang berupa angka-angka mengenai jumlah produksi dan data produk cacat. Data kualitatif yaitu data yang berupa informasi tertulis yaitu informasi mengenai jenis produk cacat, penyebab terjadinya produk cacat, bagian proses produksi, dan bahan baku yang digunakan.

2. Data sekunder, Sumber data secara keseluruhan diperoleh dari dalam masyarakat yang membuat kursi kuliah yang menjadi tempat penelitian. Data yang bersifat kuantitatif diperoleh dari data yang dicatat oleh masyarakat yang membuat kursi kuliah . Sedangkan data yang bersifat kualitatif diperoleh dari wawancara dan pengamatan secara langsung.

\section{Prosedur Pengumpulan Data}

\section{Studi pustaka}

Tahap selanjutnya adalaha studi pustaka dimana studi ini dilakukan untuk mencari teoriteori, temuan dan penelitian lain yang berkaitan dengan penelitian. Pada penelitian ini peneliti mengumpulkan informasi tentang teori Six Sigma.

2. Studi Lapangan

\section{1) Wawancara}

Merupakan suatu cara untuk mendapatkan data atau informasi dengan tanya jawab secara langsung pada orang yang mengetahui tentang objek yang diteliti. Dalam hal ini adalah dengan pihak masyarakat yang membuat kursi kuliah yaitu data mengenai jenis-jenis produk cacat dan penyebabnya, proses produksi serta bahan baku yang digunakan.

2) Observasi

Yaitu pengamatan atau peninjauan secara langsung di tempat penelitian yaitu di masyarakat yang membuat kursi kuliahdengan mengamati sistem atau cara kerja pegawai yang ada, mengamati proses produksi dari awal sampai akhir, dan kegiatan pengendalian kualitas.

3) Dokumentasi

Yaitu dengan mempelajari dokumen-dokumen perusahaan yang berupa laporan kegiatan produksi, laporan jumlah produksi dan jumlah produk cacat, rencana kerja, serta dokumen kepegawaian.

\section{HASIL DAN PEMBAHASAN}

Metode yang digunakan mengacu pada prinsip-prinsip yang terdapat dalam metode Six Sigma. Metode ini digunakan untuk mengantisipasi terjadinya kesalahan atau defect dengan menggunakan langkah-langkah terukur dan terstruktur. Dengan berdasar pada data yang ada, maka Continuous improvement dapat dilakukan berdasar metodologi Six sigma yang meliputi DMAIC (Pete\& Holpp, 2002: 45). 


\section{Define}

Six sigma merupakan alat penting bagi manajemen produksi untuk menjaga, memperbaiki, mempertahankan kualitas produk dan terutama untuk mencapai peningkatan kualitas menuju zerodefect.

Sebelum melakukan identifikasi produk cacat, terlebih dahulu ditetapkan kualifikasi mengenai produk yang bagus atau critical to quality (CTQ). Kualifikasi produk dikatakan baik sesuai dengan keinginan konsumen adalah sebagai berikut :

1. Kursi berdiri dengan sempurna

2. Tempat buku bisa dibuka dan ditutup

3. Besi dicat dengan sempurna

4. Tidak ada bekas peneglasan

Langkah awal dalam implementasi Six Sigma adalah identifikasi kegagalan produk, jika terjadi kegagalan produk, telusuri apakah penyebab dari kegagalan. Untuk menulusuri penyebab dapat menggunakan diagram aliran proses (flow process chart) pada Gambar 1.

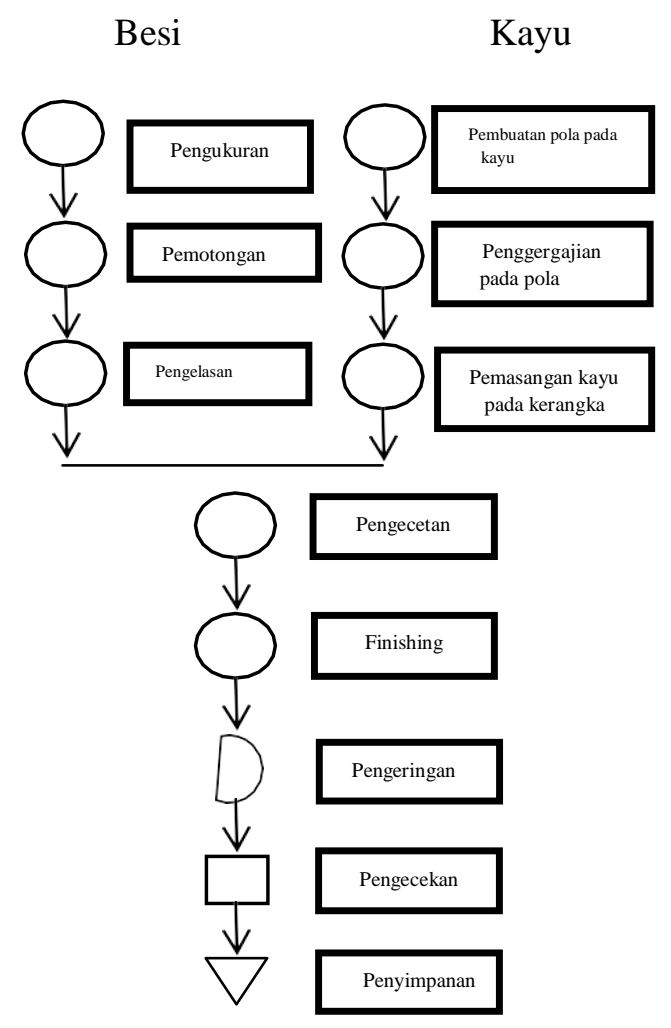

Gambar 1. Diagram aliran proses

Berdasarkan hasil dari identifikasi penyebab kerusakan, diperoleh jenis-jenis kerusakan dalam proses pembuatan kursi kuliah dari asumsi 224 sampel yang di identifikasi.

Dari identifikasi penyebab kegagalan, diperoleh jenis jenis kegagalan dalam proses pembuatan kursi. Dapat dilihat pada Tabel 1 Jenis dan jumlah kegagalan

Tabel 1. Kegagalan yang sering terjadi

\begin{tabular}{lll}
\hline 1 & Kursi Tidak Stabil & 30 \\
\hline 2 & $\begin{array}{l}\text { Kursi Tidak Kuat Pada } \\
\text { Bagian Sambungan }\end{array}$ & 20 \\
\hline
\end{tabular}


Tabel 1. Menunjukan bahwa kegagalan yang paling sering terjadi pada kursi tidak stabil dengan jumlah kerusakan 30 unit. Dalam bentuk grafik terlihat lebih jelas. Dapat dilihat pada Gambar 2.

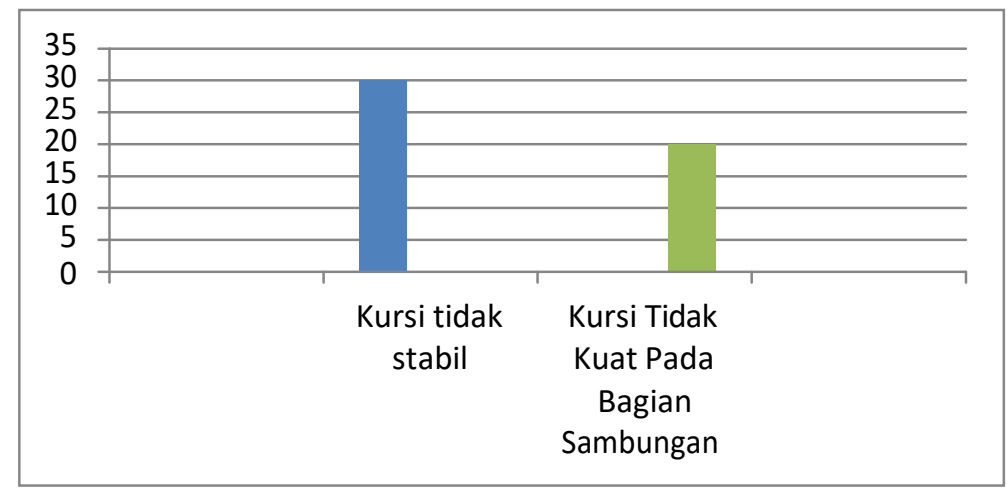

Gambar 2. Grafik Kegagalan

\section{Measure}

Six Sigma dimulai dengan penekanan cara pengukuran kualitas yang berlaku secara umum. Dalam terminology Six Sigma, sebuah cacat (defect) atau ketidak cocokan (nonconformance), adalah kekeliruan atau kesalahan yang diterima pelanggan. Unit kerja adalah output suatu proses atau tahapan proses. Kualitas output diukur dalam tingkat kecacatan per unit (defect per unit-DPU)

Untuk mengetahui posisi kualitas kursi kuliah pada level six sigma, peneliti menggunakan rumusan sebagai berikut :

\section{=NORMSINV (1 - JUMLAH CACAT/JUMLAH KEMUNGKINAN) + SHIFT}

Atau

\section{=NORMSINV $(1-$ DPMO/1.000.000) + SHIFT}

Penambahan nilai shift adalah nilai pergereseran variansi yang nantinya akan mempengaruhi nilai atau level sigma. Dimana pergeseran nilai sigma untuk level kualitas 5 sigma adalah 0,5, untuk level kulaitas 5,5 sigma adalah 1, dan untuk level kualitas 6 (six) sigma adalah 1,5 .

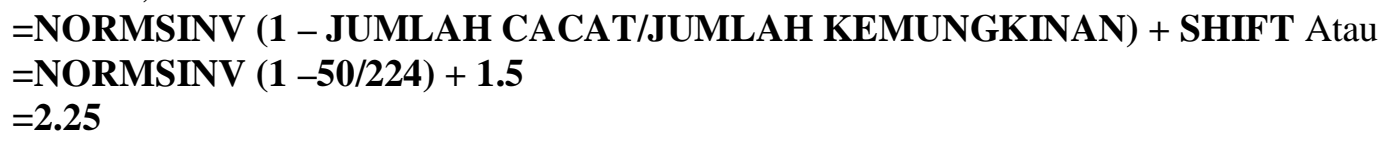

Berdasarkan hitungan penilian posisi sigma diatas produksi kursi kuliah berada pada posisi sigma 2.25 yang artinya per 1.000 .000 produksi ada sekitar 308.537 produk cacat

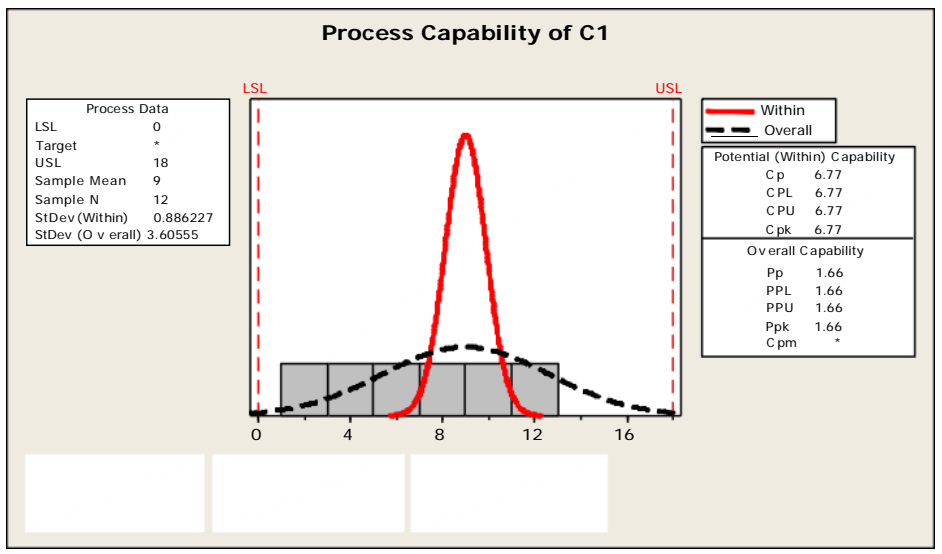




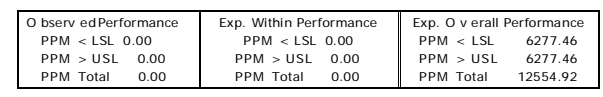

Gambar 3. Tabel Cpk

Gambar 3 menunjukkan nilai Cpk lebih besar dari 1 menunjukkan bahwa proses menghasilkan proses produksi memiliki kapabilitas yang bagus. Sehingga memiliki kemungkinan yang besar untuk menghasilkan produk yang baik, hal ini merujuk pada table estimasi kemampuan proses, dapat dilihat pada Tabel 2.

Tabel 2. Indeks kemampuan proses (Cp ) dan produk yang di luar batas-batas spesifikasi

\begin{tabular}{c|c}
\hline $\begin{array}{c}\text { Indeks kemampuan } \\
\text { proses (Cp) }\end{array}$ & $\begin{array}{c}\text { Banyaknya Proses yang berada diluar } \\
\text { kedua sisi batas batas spesifikasi }\end{array}$ \\
\hline 0,5 & $13,36 \%$ \\
0,67 & $4,55 \%$ \\
1,00 & $0,3 \%$ \\
1,33 & $64 \mathrm{ppm}$ \\
1,63 & \\
2,00 & 0 \\
\hline
\end{tabular}

\section{Analyze}

Diagram sebab akibat memperlihatkan hubungan antara permasalahan yang dihadapi dengan kemungkinan penyebabnya serta faktor-faktor yang mempengaruhinya. Adapun faktorfaktor yang mempengaruhi dan menjadi penyebab kerusakan produk. Adapun penggunaan diagram sebab akibat untuk menelusuri jenis masing-masing kecacatan yang terjadi, dapat dilihat pad Gambar 4.

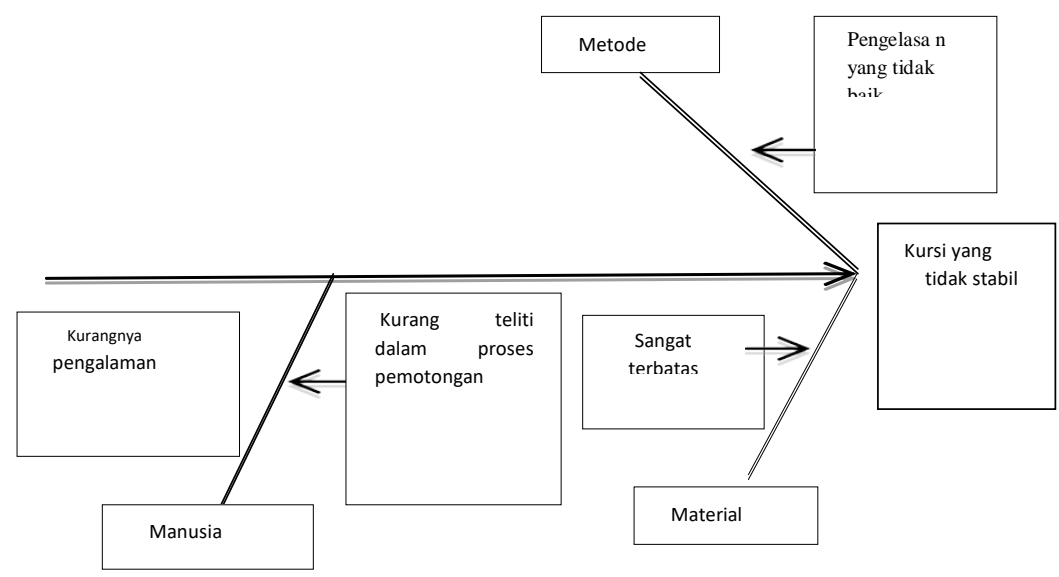

Gambar 4. Fishbone Diagram

\section{Improve}

Analisis 5W + 1H

Tabel 3. Analisis $5 \mathrm{~W}+1 \mathrm{H}$

\begin{tabular}{cll}
\hline $\mathbf{5 W}+\mathbf{1 H}$ & \multicolumn{1}{c}{ Pertanyaan } & \multicolumn{1}{c}{ Jawaban } \\
\hline What & $\begin{array}{l}\text { Apa yang menjadi masalah } \\
\text { kursi kuliah tidak stabil? }\end{array}$ & Pemasangan yang tidak siku. \\
\hline Who & $\begin{array}{l}\text { Siapa yang bertanggung } \\
\text { jawab? }\end{array}$ & $\begin{array}{l}\text { Operator pada proses } \\
\text { pemasangan kursi. }\end{array}$ \\
\hline
\end{tabular}




\begin{tabular}{cll}
\hline Why & $\begin{array}{l}\text { Mengapa kursi kuliah tidak } \\
\text { stabil? }\end{array}$ & $\begin{array}{l}\text { Karena kurang telitinya } \\
\text { operator saat pemasangan } \\
\text { kursi kuliah sehingga tidak } \\
\text { siku membuat kursi kuliah } \\
\text { tidak stabil. }\end{array}$ \\
\hline When & $\begin{array}{l}\text { Kapan terjadinya kegagalan } \\
\text { Kursi kuliah yang tidak } \\
\text { stabil? }\end{array}$ & $\begin{array}{l}\text { Pada saat proses Pemasangan } \\
\text { kursi kuliah. }\end{array}$ \\
\hline Where & $\begin{array}{l}\text { Dimana Kegagalan kerangka } \\
\text { itu terjadi? }\end{array}$ & Di proses Pemasangan. \\
\hline Bow & $\begin{array}{l}\text { Bagaimana solusi agar } \\
\text { kegagalan kursi kuliah yang } \\
\text { tidak stabil? }\end{array}$ & $\begin{array}{l}\text { Seharusnya pada proses } \\
\text { pemasangan menggunakan } \\
\text { teliti. }\end{array}$ \\
\hline
\end{tabular}

Dari Tabel 3. 5W + 1H dapat ditarik kesimpulan :Permasalahan dalam pembuatan kursi kuliah adalah kursi kuliah tidak stabil. Membuat kursi tidak siku, dalam masalah kegagalan produk kursi kuliah ini terjadi dalam proses pemasangan, dan orang yang bertanggung jawab adalah operator karena kurang telitinya saat pemasangan kursi kuliah sehingga kursi tidak siku membuat kursi tidak stabil. Solusinya operator harus lebih teliti dan menggunakan penggaris siku pada saat pemasangan kursi

\section{Control}

Langkah terakhir dalam mengimplementasikan six sigma untuk meningkatkan kualitas produk adalah dengan membuat grafik pengendali kualitas, karena jenis data pada penelitian ini merupakan data atribut maka dari itu jenis grafik kendali kualitas yang digunakan adalah grafik pengendali kualitas $p$, dan berikut adalah Gambar 5 yang menunjukkan pengendali $p$ dari data produk cacat dengan menggunakan minitab15

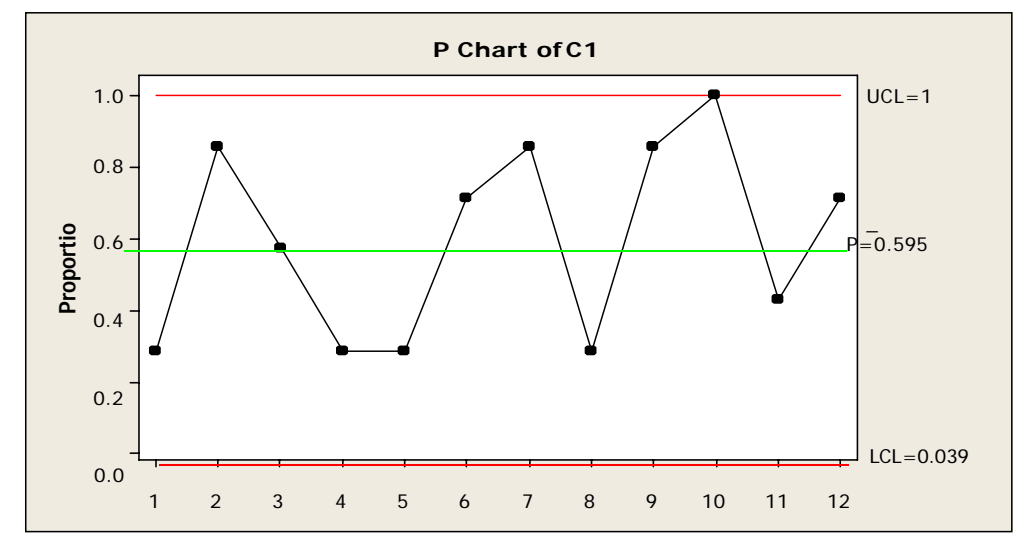

Gambar 5. Grafik Pengendalian kualitas

\section{KESIMPULAN}

Berdasarkan deskripsi diatas, maka rumusan masalah dalam penelitian ini adalah bagaimana Implementasi Metodologi Six Sigma Untuk Meningkatkan Kualitas Produk Kursi Kuliah.

1. Kegagalan yang paling sering terjadi pada kursi tidak stabil dengan jumlah kerusakan 30 unit.

2. Dari grafik di atas nilai Cpk lebih besar dari 1 menunjukkan bahwa proses menghasilkan proses produksi memiliki kapabilitas yang bagus. Sehingga memiliki kemungkinan yang 
besar untuk menghasilkan produk yang baik, hal ini merujuk pada table estimasi kemampuan proses dibawah ini.

3. Faktor-faktor yang mempengaruhi dan menjadi penyebab kerusakan produk secara umum dapat digolongkan pada diagram fishbone adalah Manusia, Metode, Material.

4. Permasalahan dalam pembuatan kursi kuliah adalah kursi kuliah tidak stabil. Membuat kursi tidak siku, dalam masalah kegagalan produk kursi kuliah ini terjadi dalam proses pemasangan, dan orang yang bertanggung jawab adalah operator karena kurang telitinya saat pemasangan kursi kuliah sehingga kursi tidak siku membuat kursi tidak stabil. Solusinya operator harus lebih teliti dan menggunakan penggaris siku pada saat pemasangan kursi.

Langkah terakhir dalam mengimplementasikan six sigma untuk meningkatkan kualitas produk adalah dengan membuat grafik pengendali kualitas, karena jenis data pada penelitian ini merupakan data atribut maka dari itu jenis grafik kendali kualitas yang digunakan adalah grafik pengendali kualitas.

\section{DAFTAR PUSTAKA}

Gasperz, V. (2005). Total Quality Management. Jakarta : PT. Gramedia Pustaka Utama. Gasperz, V. (2007). Lean Six Sigma. Jakarta : PT. Gramedia Pustaka Utama.

Heizer, Jay \& Render, B. 2006. Operations Management (Manajemen Operasi). Jakarta : Salemba Empat.

Latief, Y. \& Utami, R. P. (2009). Penerapan Pendekatan Metode Six Sigma Dalam Penjagaan Kualitas Pada Proyek Konstruksi. Makara Teknologi. Volume 13 No.2 67-72. Universitas Indonesia, Depok

Nasution, M. N. (2005). Manajemen Mutu Terpadu. Bogor : Ghalia Indonesia.

Pande, Neumann, \& Cavanagh, R. R. (2002). The Six sigmaWay Bagaimana GE, Motorola \& Perusahaan Terkenal Lainnya Mengasah Kinerja Mereka. Yogjakarta : ANDI.

Pete \& Holpp. (2002). What Is Six Sigma. Yogjakarta : ANDI.

Reksohadiprojo, Soekanto \& Sudarmo, I.G. (2000). Manajemen Produksi. Yogjakarta : Edisi keempat. BPFE

Sugiyono. (2004). Metode Penelitian Bisnis. Bandung : CV Alfabeta

Susetyo, J (2011). Aplikasi Six Sigma DMAIC Dan Kaizen Sebagai Metode Pengendalian Dan Perbaikan Kualitas Produk. Jurnal Teknologi. Volume 4 No.1 61-53. Institut sains \& Teknologi AKPRIND, Yogyakarta 